\title{
AIR MISSION COMMANDER. COMMAND AND CONTROL
}

\author{
Mihai IORDACHE \\ Defence Staff, Bucharest, Romania \\ iordache.dmihai@gmail.com
}

\begin{abstract}
In the fight management, the military commander, who is assimilated to a leader has, most of the time, the most important role. Today, in addition to the traditional missions to defend the sovereignty, independence and territorial integrity of the state, the military forces also carry out missions according to the obligations assumed by NATO or EU membership: peacekeeping, peace enforcement, humanitarianism, post conflict reconstruction, terrorism, security and collective defense. These missions require the adoption of modern forms and methods of leadership, especially as they are largely executed outside the national territory, which provokes new cultural expectations and demands, involves ethical issues and legal advice whose value is not fully known.
\end{abstract}

KEYWORDS: air mission, command, commander, control, tactical C2

\section{Introduction}

Generally, when we look at the

profile of an effective military leader, we consider a few features that he has to meet: intelligence, competence, integrity, equity, benevolent attitude, spiritual opening, progressive thinking and courage. In addition to these traits, the commander of the military force in a theater of operations must prove certain types of behavior in order to be able to impose his influence on the other members of the military entity. There are more and more types of behavior in the literature: authoritarian, directive, based on reward and conditional punishment, facilitation, persistence, supportive, participative, delegation, permissive, and the achievement-oriented influence process (Builder, Bankes, Nordin, 1999).

In a multinational force, the Joint Force Commander (JFC) becomes the commander of multinational force; a Joint Force Air
Component Commander (JFACC) is appointed as commander of the multinational air component. Similarly, an Air Operations Center (AOC) or Joint Air Operation Center (JAOC), when referring to the level of joint forces, is transformed into a multinational Combined Air Operations Center (CAOC) with a representation that, like a JAOC, respects the format of force.

Air Force needs to invest in the development of decisive mission commanders to manage the degraded multi-domain operations we expect to see in the developing security environment and this investment must be in the form of improving or upgrading platforms and improving training.

\section{Air Mission Commander}

Commanders of multinational operations should take into consideration the next items: 
- Respect. When allocating missions, the commander should assume that respect and national prestige can be equally significant for a contributing nation such as combat potential. Every partner must be involved in the planning phase, and their views have to count on mission allocation.

- Relationships. Commanders and staff must initiate relationships with representatives of partner nations. This involves personal, direct relationships with counterparts that can be developed only by them.

- Partner knowledge. Commanders and staff must know every multinational force member. It takes time and effort to know the adversary; an almost identical struggle is needed to comprehend the doctrine, strategic objectives, capabilities, culture, customs, religion, values and history of each member.

- Patience. Effective partnerships require time and attention to be developed. Looking for a trustworthy, common interest relationship with other partners involves unusual and unwavering patience. This is more problematic to achieve within coalitions than inside alliances, nevertheless it is demanded.

- Focus on mission. While working with other members, forces must mitigate the need for respect, relationship, patience, and knowledge, with the necessity to make sure that the mandatory tasks are met by those who have the capacity and authority to do so. It is particularly important on the security line of operations, where failure could have fatal consequences.
- Faith. Commanders must approach counterpart heads of multinational force to develop personal connections and boost mutual confidence. Growing these interconnections is a responsive act of collaboration. Commanders give confidence through words and actions.

Future fights will not be carried on a single battlefield. These will be multi-domain - fought on/from sea, space, cybernetic and air, all at the same time. A common picture, a common goal and a common mission create the ability to fight anytime, anywhere, and win.

The emerging security environment and future threats that highlight multi-domain operations will try to degrade the operational environment by giving opponents the ability to take the initiative, as operators attempt to re-establish connectivity between tactical and operational levels. However, this problem can be counteracted by producing missionoriented tactical commanders at the tactical level, capable of implementing operational measures in real-time decision-making that lead to the success of the mission.

Tactical Command and Control (TAC C2) platforms are ideal to serve as mission commander. These platforms are operational/ on-station for a long time, which allows them to maintain continuity for the entire operation without the limitations of fuel, commonly performed by commanders performing missions on other platforms (fighters, for example). In addition, for decision making, these platforms have the advantage of having multi-radio communications (including SATCOM, UHF, VHF and HF frequencies), radar, identification friend or foe systems (IFFs), tactical chat, data links and a variety of other systems. In addition to providing good knowledge of the battlefield, these systems also allow AOC connectivity, which exceeds the visual range of other 
tactical platforms, allowing TAC C2 to serve as a bridge between operational and tactical levels of warfare, transforming operational guidance into tactical decisions at a rate that will allow their own forces to operate in a decision-making cycle that exceeds that of opponents, allowing the initiative to be maintained.

Also, TAC C2 platforms use a variety of individuals (usually over 16 members) in different environments, and these crews operate in a non-threatening environment and are typically protected by a layered defense plan (i.e. aircraft, surface to air missile systems, etc.). Such an environment offers crew members an ideal atmosphere to solve problems and generate quick tactical solutions for dynamic events with the bonus of using the expertise of many individuals. Such an environment is necessary to process and act properly on the flow of entries that will be present in multi-domain operations.

If we agree that the success of a mission commander is based on platform capabilities and training, then the natural question is: how does Air Force or NATO prepare decisive mission commanders to succeed in tomorrow's multi-domain operations?

For airborne platforms, it is obvious that fleet ageing needs to be solved because many of these platforms have exceeded the projected lifespan. In addition, as the war moves beyond the counter-insurgency, it is imperative that the upgrades of the TAC C2 platforms to keep up with the technology, to provide mission commanders running these platforms access to all available data to make decisions.

Training needs to develop the intangible skills needed to be a mission commander:

- to understand and apply the commander's intent;
- to understand the acceptable limits of risk (ALR) and how to maintain the tactical execution within these limits;

- to generate real-time solutions for dynamic events that are consistent with the commander's intent;

- to understand the assumptions on which a plan is based and recognize and overcome a mistaken or inaccurate hypothesis;

- to make robust decisions, but also recognize when a decision must be made;

- to recognize when an informational input is false or incomplete.

The final outcome of these adjustments in preparation will form an agile mission commander who is able to gather and process more information and act decisively to generate tactical solutions to achieve the commander's intention within an ALR.

\section{Command and Control (C2)}

International military operations are one of the main ways of engaging and managing forces for crisis management, have a strong politico-military character, are within the law and fully legitimate. Military actions are conducted in accordance with the laws of the armed warfare and the norms of international humanitarian law and are subject to unpredictable interferences and changes. This leads to the adoption of a highly reliable and adaptable management system, which ensures the accomplishment of the missions by means of knowledge and thorough understanding of the $\mathrm{C} 2$ act, the command and the order as action, so that it will permanently contribute to the improvement and the efficiency of the military actions (Cornescu, Mihăilescu \& Stanciu, 2003). 
The political leadership of international military operations is the one that imposes, through the mandate entrusted to the military, the achievement of the objectives and at the same time directs the international armed actions from the strategic level to the tactical level.

The unity of command is the principle according to which the acquisition of the power to direct and coordinate the activity of all forces, means and resources is accomplished by one person, the force commander, authorized by a legal act issued by the international authority that has mandated the multinational force and is indispensable for effective operational engagement of multinational force. In favor of ensuring the unity of command, the commander of the multinational military force must, as a minimum requirement, have at least operational control (OPCOM) over all the assigned or attached forces (Human Resources Management in the Romanian Armed Forces, 1998).

C2 means "exercising authority and leadership by a commander over the forces assigned and attached to accomplish the mission" (NATO, 2011, pp. 1-12). In practice, the $\mathrm{C} 2$ process is accomplished through a staff, facilities, communications, equipment and procedures distribution used by a commander to schedule, appoint, coordinate and control operations and forces to fulfill the mission.

The concept of "command" has been used since ancient times and it is generally well understood. This concept is defined as "the authority invested in an individual of the armed forces for directing, coordinating and controlling military forces" (NATO, 2015 , p. 2). All or part of this power may be assigned to lower commanders in the chain of command.

The order includes both authority and responsibility for the actual use of obtainable resources to reach the desired results. Command at all levels is to guide persons and structures into action. The skill of ordering consists of the aware and competent employment of command authority in decision-taking and supervision, as well as the use of perspicacity and instinct gained from training, experience, education and innovative thinking.

Commanders view the circumstances and make firm and rapid decisions. Successful decision-making integrates wisdom with facts and it is necessary to know whether to decide, what to decide and when to decide. Rapidity in thinking and decision is needed to keep the initiative on the opponent. The decision is both art and science (NATO, 2011).

Control is "the authority exercised by the commander on parts of the activity of subordinate organizations or other organizations not ordinarily under his command which includes responsibility for the enforcement of orders or directives" (NATO, 2011, p. 2). All or part of this power may be transferred to commanders in the chain of command.

The control of forces and functions supports commanders and staff to determine demands, allocate resources and achieve results. This authority enables the commander to work, assign authority and position himself in the proper situation to supervise, evaluate and lead. Finally, it allows commanders the means to efficiently and effectively use common forces to accomplish goals and reach the end condition (NATO, 2011).

Control provides a mean of exercising an efficient command. During air operations, the control is usually shown in the authority to assign missions through the Air Tasking Order (ATO), a document that organizes the collective effort of a potentially complex air campaign. ATO 
allows a single commander to efficiently task a large number of units/squadrons, normally dispersed both inside and outside a theater of operations.

A good understanding of authority levels is a requirement for successful collaboration within NATO military command structures.

Air forces must be organized on solid C2 principles in order to obtain operational effectiveness across the full spectrum of conflict. Centralized control is necessary to ensure the most efficient use of limited air assets by allowing a rapid reorientation of air power to utilize transient options to meet the changing operational needs and priorities and to concentrate in critical time and place to reach decisive outcome. The decentralized execution of air operations allows designated activities and actions to be carried out at the same time by lower level commanders in different locations.

Centralized control provides coherence, orientation and organization of the use of air power. This is done through a single officer, having a theater perspective, which has the authority to assign missions to the air forces to achieve the best goals. $\mathrm{He}$ is responsible for control (including planning, targeting, prioritizing, allocating, synchronizing, integrating and de-conflicting) all assigned or temporarily assigned air forces. It is important that he normally does not have to command assigned air forces because it is the control that allows the assignment of air force missions.

Decentralized execution is the authority delegated to lower commanders to execute assigned tasks and it is subject to commander's intent, rules of engagement (ROE) and other parameters set by higher command. Decentralized execution favors initiative and accountability and gives subordinate commanders the authority to apply their experience and understanding of local conditions to fulfill the mission within the commander's direction and intent. Generally, the more decentralized this command is in an air operation, the more likely the missions, details and variables are to be met.

In addition to centralized control and decentralized execution, the British add two more principles: centralized planning and exercise of control at the highest practical level (Centre for Air Power Studies Royal Air Force).

Centralized air assets' planning is required to ensure an integrated approach to the general objectives of the campaign. This will prevent small and inefficient packages of air assets from being split up, which could hamper rapid concentration of force and flexibility.

Thus, the utilization of limited air assets can be condensed to achieve the requirements of the campaign as a whole or at the decisive time and place to reach determining outcome.

The unity of air effort can best be reached when the $\mathrm{C} 2$ authority is exercised at the highest practical level, depending on goals, available resources and $\mathrm{C} 2$ engagements. As C2 systems become faster, more reliable and more active, there will be increased allocation alternatives available to commanders.

Effective $\mathrm{C} 2$ requires persistent coordination and execution activities.

Continuous activities are necessary during aerospace operations and include:

- Monitoring: The processes of observing and reporting the entire spectrum of operational area factors to ensure accurate situational awareness;

- Estimation: the process of assessing performance and capabilities of persons, materials or systems, for counseling the commander; 
- Planning: the logical process through which management decisions are made.

Execution activities occur periodically during aerospace operations and include:

- Direction: command authority act that provides instructions specific to subordinates and support units. Commanders must provide all necessary guidance to maximize efficiency and effectiveness, and to reduce uncertainty across the spectrum of the conflict. Direction should also provide subordinate commanders with the opportunity to exercise their initiative to harness the opportunities present in the tactical environment;

- Coordination: Exchange of information for consensus and organization of activities. Effective coordination should integrate, synchronize and de-conflict operations between different organizations. Normally, commanders at all levels delegate considerable authority to subordinate staff to coordinate airspace operations.

\section{Conclusion}

In recent years, there has been a growing and quite justifiable discussion about management as a way of operating an organization or a field. Human activity, in its dynamics, demonstrates that the way of adopting effective decisions on the leadership of some organizations depends to a large extent, on the efficiency of the management that is implemented, which in turn must ensure suppleness, flexibility, efficiency, economy, etc.

Achieving unity of effort demands a comprehensive approach that involves coordinating, strengthening consensus, cooperating, collaborating, compromising, consulting and de-conflicting all stakeholders to achieve an objective. Close collaboration with partners is often more proper than a C2-focused military approach. Taking an authoritative decision can be counterproductive to interorganizational relationships, may prevent unity of effort and compromise the fulfillment of the mission. Also, a constant effort is needed to support interorganizational relationships.

Command and control (C2) of NATO air operations in Europe and beyond requires the integration of a number of components and services at all command echelons to efficiently assign combat or support aircraft, unmanned aerial vehicles and surface-to-air missiles.

In air force, Battle Management, Command and Control (BMC2) is the art of translating real-time combat space awareness, operational orientation and combat potential into decisive tactical action through a wide range of missions, including air-to-ground, air-to-air and support missions. Within NATO, BMC2 systems are directly related to the exercise of decentralized execution. Specifically, NATO AWACS crew has tactical authorities delegated that allow tactical action based on real-time information. This delegation allows NATO Airborne Warning and Control System (AWACS) crews to operate independently from the NATO Air C2 structure.

Centralized command and decentralized execution will continue to be important for military operations supported by the leadership philosophy of the mission commander as a prerequisite for networkbased operations. The independence of $\mathrm{BMC} 2$ is ensured by command arrangements of (CAOC). Centralized control cannot reach the farthest point of the battle space. The delegation of tactical control to BMC2 systems fulfills the commander's intent by gaining and maintaining the initiative. Therefore, BMC2 should be integrated both horizontally and vertically to maximize information sharing and merger. 


\section{REFERENCES}

Builder, C. H., Bankes, S. C., \& Nordin, R. (1999). Command Concepts - A Theory Derived from the Practice of Command and Control. Washington, D.C.: RAND.

Centre for Air Power Studies Royal Air Force. British Air and Space Power Doctrine: AP 3000 Fourth Edition.

Cornescu, V., Mihăilescu, I., \& Stanciu S. (2003). Managementul Organizaţiei. Bucureşti: Editura ALL BECK.

North Atlantic Treaty Organization (NATO). (2011). AJP-3 (B), Allied Joint Doctrine for the Conduct of Operations. 1-12, NATO Standardization Office (NSO).

North Atlantic Treaty Organization (NATO). (2015). AAP-06, NATO Glossary of Terms and Definitions. NATO Standardization Office (NSO).

Onişor, C. (1999). Teoria strategiei militare. Bucureşti: Academia de Înalte Studii Militare. 